\title{
Does the removal of finder's share influence the scrounging decisions of herbivores?
}

\author{
Ryan B. Kok, Keenan Stears ${ }^{\#}$, Adrian M. Shrader*
}

School of Life Sciences, University of KwaZulu-Natal, Private Bag X01, Scottsville, 3209.

*Corresponding author and current address: adrian.shrader@up.ac.za, Mammal Research Institute, Department of Zoology \& Entomology, University of Pretoria Phone (w): +27 12420 3232, Fax: +27 123625242

\#Current address: Department of Ecology, Evolution, and Marine Biology, University of California Santa Barbara, USA

\section{Highlights}

- It is unclear if herbivores use finder's share when making patch-joining decisions.

- We manipulated finder's share and food availability to explore these decisions.

- At low food availability, goats avoided the finder's share patch after $30 \mathrm{~s}$.

- When food availability was high, goats continued to join the finder's share patch.

- Thus, both finder's share and food availability influenced patch-joining decisions.

\begin{abstract}
Group-living animals use social information when making patch-joining/ scrounging decisions. However, the extent to which they use finder's share (i.e. amount of food eaten in a patch before other individuals arrive) as a cue when making these decisions is unknown. It is likely that the removal of finder's share decreases patch attractiveness to scroungers. However, it is unclear how large a finder's share must be to reduce attractiveness, or how this varies with food availability. To answer these questions, we recorded the patch-joining decisions of dominant goats (Capra hircus) when presented with a choice between an artificial patch where finder's share had been removed by a subordinate patch holder
\end{abstract}


(producer), and one where the patch holder had just started eating. We used time spent feeding by a patch holder $(10,30,60$ and $120 \mathrm{sec})$ as an index of finder's share size, and tested this using three food availabilities (40 g, $100 \mathrm{~g}, 300 \mathrm{~g})$. At low (40 g) and intermediate (100 g) food availabilities, scrounging goats avoided the finder's share patch once the patch holder had fed for $\geq 30$ seconds (i.e. $25 \%$ and $17 \%$ of the food removed respectively). However, at the highest food availability (300 g), these goats continued to join the finder's share patch even after the patch holder had fed for $120 \mathrm{~s}$ (18\% removed). Ultimately, our results indicate that goats weigh up both food availability and the finder's share when making scrounging decisions. Nevertheless, finder's share removal was less important in patches with more food.

Keywords: feeding time, food availability, foraging, goats, group living

\section{Introduction}

There are both benefits and costs to group living (Krause \& Ruxton, 2002). Benefits include reduced predation risk (Lima, 1990; Schmitt, Stears, Wilmers \& Shrader, 2014; Schmitt, Stears, \& Shrader, 2016), and greater feeding efficiency due to social information (Valone, 1989; Valone \& Templeton, 2002; Shrader, Kerley, Kotler, Brown, 2007). For example, by watching other group members, individuals can gain a greater understanding about the environment beyond their own personal information (Giraldeau, Valone, \& Templeton, 2002; Valone \& Templeton, 2002). This allows group members to feed more efficiently and have greater access to high quality patches (Shrader et al., 2007). Moreover, individuals can use social information to locate feeding group members and then join them at their patches (i.e. Giraldeau et al., 2002). However, this can result in the cost of increased competition within these patches. 
One way to explore patch-joining decisions of individuals is by using game theory in the form of producer-scrounger games (Barnard \& Sibley 1981; Giraldeau \& Beauchamp 1999). In these games, an individual can either search for food patches (produce), or join other individuals at their patches (scrounge) (Beauchamp 2008; Ohtsuka \& Toquenaga 2009). When making scrounging decisions, individuals weigh up a range of factors including the quantity and quality of food in a patch, and the dominance status of the patch holder (Barnard, 1984; Stears, Kerley, \& Shrader, 2014). Generally, dominant individuals join subordinates at feeding patches (Liker \& Barta, 2002; King, Isaac, \& Cowlishaw, 2009). In response, subordinate individuals can increase their intake rate to ensure they obtain a greater proportion of food in a patch prior to scroungers joining them (i.e. the finder's share) (Vickery et al., 1991; Shrader et al., 2007).

Key factors that affect finder's share include the amount of food in the patch (Di Bitetti \& Janson, 2001) and the amount of time available to the patch holder to eat before a competitor arrives (Vickery et al., 1991). To date, theoretical and empirical exploration of the impact of finder's share on the foraging decisions of group-living animals have focused mainly on how the size of the finder's share removed influences the overall foraging strategies of group members. For example, how increasing finder's share obtained by producers (i.e. individuals that find food patches) decreases the benefits of scrounging (e.g. Caraco \& Giraldeau, 1991; Giraldeau \& Livoreil, 1998; Hamilton, 2002). In response to this increasing finder's share, individuals are predicted to change their overall foraging strategy and search for their own patches (i.e. shift from acting as scroungers to acting as producers; Giraldeau \& Caraco, 2000). However, one aspect that has not been considered is that individuals may not change their overall foraging strategy in response to changing finder's share. Rather, they may simply scrounge from a different individual within the group at a patch where less food has been removed (i.e. smaller finder's share). If this is the case, then 
variability in finder's share may play a large role in influencing the patch-choice decisions of scrounging individuals.

With many group members feeding simultaneously (Valone, 1989; Valone \& Templeton, 2002), it is likely that the time each of these individuals started feeding in a patch, and thus the amount of food they have removed at any specific point in time, varies. Hence, it may be more beneficial to join certain patches rather than switch foraging strategies and incur the costs of searching for a new patch. If this is the case, then how do scroungers determine which patch to join? Food availability within patches is not constant across the landscape. Thus, the impact of the removal of the finder's share will likely vary with the amount of food in the patch. As a result, the size of the finder's share removed should ultimately influence the patch-joining decisions of scroungers across a range of different patches. However, the degree to which herbivores use finder's share as a cue for making patch-joining decisions has not been explored (Di Bitetti \& Janson, 2001).

To address this, we ask: (1) what is the relationship between food availability, feeding time, and the finder's share? (2) Do scrounging herbivores use the finder's share obtained by a patch holder (i.e. producer) as a cue for making patch joining decisions (i.e. patch attractiveness), and if so, (3) how does the influence of finder's share on patch-joining decisions vary with food availability in a patch? If scrounging herbivores do not utilise finder's share as a cue, then we would expect that the amount of time a patch holder feeds within a patch (i.e. an index of finder's share) should not influence patch choice by scrounging individuals. In contrast, if finder's share does play a role, individuals should prefer to join patches where the patch holder has fed for less time, and thus obtained less food (i.e. small finder's share; Giraldeau, Hogan, \& Clinchy, 1990). In addition, as feeding in a patch reduces food availability, the influence of finder's share removal on patch-joining decisions should be greater in patches with less food. This is because by feeding in these 
patches, patch holders remove a greater proportion of the available food, and thus reduce food availability and likely patch attractiveness for scroungers. Therefore, we predict that scrounging herbivores should tolerate larger finder's shares being obtained (i.e. patch holder feeding for longer) in patches with greater food availability compared to patches with lower food availability.

\section{Methods}

We ran the study during May-July 2013 at Ukulinga Research Farm, Pietermaritzburg, South Africa. The University animal ethics committee cleared the experimental procedures (reference number 015/13/Animal), and no animals were hurt during the experiments.

To explore how the removal of the finder's share affected the patch-joining decisions of scrounging herbivores, we recorded the patch-joining decisions of $19\left(11 \delta^{\Uparrow} ; 8 \bigcirc\right)$ dominant indigenous veld goats (Capra hircus) from a single herd of 43 individuals. Prior to these experiments, we trained these dominant goats to associate the different colours and shapes of artificial patches with different food quantities. Thus, their patch-joining decisions were based off this prior knowledge. All individuals in the herd were familiar with each other prior to the start of our experiment, and none of the females in the herd were lactating. We focused on the scrounging choices of dominant individuals because they are more likely to join patches of other group members (Barta \& Giraldeau 1998; Liker \& Barta, 2002). Goats provide a good model to test our predictions because they learn quickly (Cote, 2000), and use social information and the availability of food in a patch when making patch joining decisions (Shrader et al., 2007; Stears et al., 2014).

In line with standard practices in South Africa (see Shrader, Kerley, Brown, \& Kotler, 2012), the goats were held in a barn (30 x $12 \mathrm{~m})$ overnight where they had ad lib access to water, but no food. In the mornings prior to the experiments, we moved the goats into a rye 
grass paddock and allowed them to feed for 30 minutes. This allowed them to become partially sated and thus reduce the effect of hunger on the results. We then ran experiments from $7 \mathrm{~h} 00$ to $11 \mathrm{~h} 00$. After the experiments, we released the goats into a natural grassland where they fed for $\sim 6$ hours before returning to the barn.

\section{Dominance relationships}

To identify dominant individuals in the herd (Table 1), we followed the same procedure outlined in Stears et al. (2014) to establish a dominance hierarchy for the goat herd (see Stears et al. 2014, for details). As with Stears et al. (2014), we determined dominance by staging interactions between two individuals. We did this by providing an artificial food patch (L x W x H: 57.0 x 36.5 x $23.0 \mathrm{~cm})$ containing $200 \mathrm{~g}$ of commercial sheep food (Complete Sheep Finisher, Meadow Feeds, South Africa) to the two goats. To reduce the risk of injury, we staged the interactions within a $700 \times 450 \mathrm{~cm}$ pen, which provided enough space for subordinate individuals to move away from aggressive dominant individuals. We released the goats from opposite sides of the food patch and determined dominance by observing the behavioural interactions of the two goats over a one-minute period (see Stears et al., 2014). We did this, as all interactions tended to take place within the first $30 \mathrm{sec}$. We classified goats that initiated aggressive behaviours (e.g. horning, head-butting) and/or monopolised the patch as being dominate. In contrast, those that moved away from or refused to join the patch, were classified as subordinate. We then used this information to calculate a win-loss matrix and goats were ranked according to David's Score (Gammell, De Vries, Jennings, Carlin, \& Hayden, 2003; Bang, Deshpande, Sumana, \& Gadagkar, 2010). 
Table 1. Sex, presence of horns, and dominance rank of individuals in the goat herd.

\begin{tabular}{|c|c|c|c|c|}
\hline Goat ID & Sex & Horns & Dominance rank & Status $^{1}$ \\
\hline Blue05 & $\mathrm{M}$ & Yes & 1 & Dominant \\
\hline IG18 & $\mathrm{M}$ & Yes & 2 & Dominant \\
\hline IG35 & $\mathrm{M}$ & Yes & 3 & Dominant \\
\hline IG41 & $\mathrm{M}$ & Yes & 4 & Dominant \\
\hline Blue06 & $\mathrm{M}$ & Yes & 5 & Not used \\
\hline Blue04 & $\mathrm{M}$ & No & 6 & Dominant \\
\hline IG1 & $\mathrm{F}$ & Yes & 7 & Dominant \\
\hline Mottled & $\mathrm{F}$ & Yes & 8 & Dominant \\
\hline Matey & $\mathrm{F}$ & Yes & 9 & Dominant \\
\hline IG36 & $\mathrm{M}$ & Yes & 10 & Dominant \\
\hline IG32 & $\mathrm{F}$ & No & 11 & Dominant \\
\hline Blue03 & $\mathrm{F}$ & Yes & 12 & Dominant \\
\hline IG22 & $\mathrm{F}$ & No & 13 & Dominant \\
\hline IG42 & $\mathrm{M}$ & No & 14 & Dominant \\
\hline Blue02 & $\mathrm{F}$ & Yes & 15 & Dominant \\
\hline TK1 & $\mathrm{M}$ & Yes & 16 & Dominant \\
\hline Blue08 & $\mathrm{M}$ & No & 17 & Dominant \\
\hline IG46 & $\mathrm{M}$ & Yes & 18 & Dominant \\
\hline Blue01 & $\mathrm{F}$ & No & 19 & Dominant \\
\hline IG57 & $\mathrm{M}$ & Yes & 20 & Dominant \\
\hline IG51 & $\mathrm{M}$ & No & 21 & Not used \\
\hline TK7 & $\mathrm{F}$ & Yes & 22 & Not used \\
\hline TK2 & $\mathrm{M}$ & Yes & 23 & Not used \\
\hline Blue07 & $\mathrm{F}$ & No & 24 & Not used \\
\hline IG55 & $\mathrm{F}$ & Yes & 25 & Not used \\
\hline IG44 & $\mathrm{F}$ & No & 26 & Subordinate \\
\hline TK6 & $\mathrm{F}$ & No & 27 & Subordinate \\
\hline TK8 & $\mathrm{M}$ & Yes & 28 & Subordinate \\
\hline Blue11 & $\mathrm{F}$ & Yes & 29 & Subordinate \\
\hline TK5 & $\mathrm{F}$ & No & 30 & Subordinate \\
\hline TK3 & $\mathrm{F}$ & No & 31 & Subordinate \\
\hline TK4 & $\mathrm{F}$ & No & 32 & Subordinate \\
\hline Blue14 & $\mathrm{M}$ & Yes & 33 & Subordinate \\
\hline IG28 & $\mathrm{F}$ & No & 34 & Subordinate \\
\hline IG29 & $\mathrm{M}$ & Yes & 35 & Subordinate \\
\hline IG30 & $\mathrm{M}$ & Yes & 36 & Subordinate \\
\hline IG31 & $\mathrm{F}$ & No & 37 & Subordinate \\
\hline IG35 & $\mathrm{M}$ & Yes & 38 & Subordinate \\
\hline IG36 & $\mathrm{M}$ & Yes & 39 & Subordinate \\
\hline IG38 & M & No & 40 & Subordinate \\
\hline IG39 & $\mathrm{M}$ & No & 41 & Subordinate \\
\hline IG12 & $\mathrm{M}$ & Yes & 42 & Subordinate \\
\hline IG13 & $\mathrm{F}$ & No & 43 & Subordinate \\
\hline
\end{tabular}

${ }^{1}$ Dominant scroungers, and subordinate patch holders. 
Three factors that could potentially influence our experiments were, 1) the relatedness of individuals, 2) sex of patch joiners and patch holders, and 3) whether individuals had horns or not. The genetic relatedness of all individuals in the goat herd was not available, thus it is likely that we tested dominance between related individuals. However, when we staged interactions between individuals that we knew to be related, aggressive interactions took place and a dominant individual was always able to be identified. Despite this, we never directly tested individuals that we knew to be related in the patch-joining experiments (see below).

Stears et al. (2014) found that the sex of the joining individual, as well as the sex of the patch-holding individual, did not influence patch-joining behaviour. In our study, dominant and subordinate individuals comprised individuals of both sexes (Table 1). Thus, neither patch-joining nor patch-holding were restricted to a specific sex. Lastly, the presence of horns was randomly distributed throughout the goats' hierarchy (Table 1). This was similar to Aschwanden et al. (2008) who found no correlation between the presence of horns and patterns in dominance structures. In addition, the presence of horns has been shown to have no influence on the degree of agnostic interactions during feeding (Loretz, Wechsler, Hauser, \& Rüsch, 2004). As a result, relatedness between individuals, sexes of the joining and patch holding goats, and the presence of horns were not included in our statistical models.

\section{Patch choice between different food availabilities}

Once we had ranked the goats, we conducted patch choice experiments in a $700 \mathrm{x} 450 \mathrm{~cm}$ pen (i.e. testing arena; Figure 1). We covered the walls of this arena with black plastic to ensure that the goats focussed on the experiment (Figure 1). Similar to Stears et al. (2014), we divided the back portion of the pen in half using a $3 \mathrm{~m}$ non-transparent fence covered in black plastic. On each side of this divider, we then tethered a subordinate goat to the back wall 
using a dog collar and rope. This prevented these animals from leaving their side of the pen. In front of each subordinate, we placed an artificial food patch from which they could feed (Figure 1).

\section{$450 \mathrm{~cm}$}

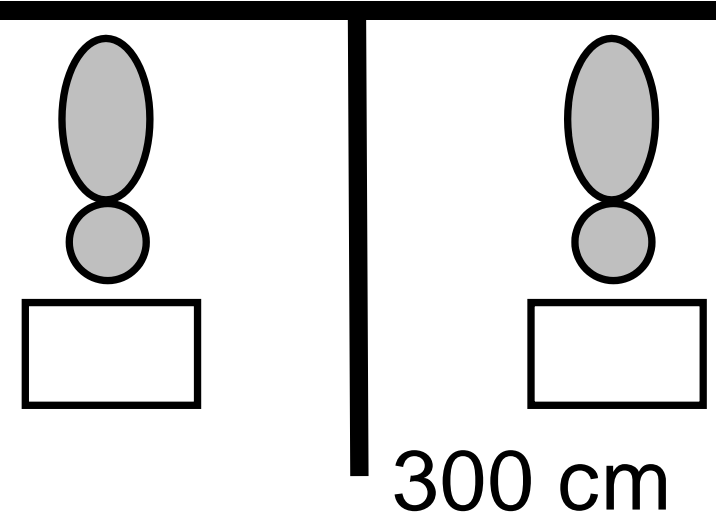

\section{$700 \mathrm{~cm}$}

Figure 1. Testing arena $(450 \mathrm{~cm} \mathrm{X} 700 \mathrm{~cm})$ used in the choice experiments. Black lines denote non-transparent fences. Feeding patches (open rectangles) were placed at the back of the area on each side of the $(300 \mathrm{~cm})$ nontransparent divider, in front of tethered goats (grey circles). The test goat (grey circles at the bottom of figure) was then released from the front of the area. 
To test the effect of the removal of the finder's share from different patches, we used three different artificial patches that varied in food availability. The first was a rectangular black plastic tray $(57 \times 36.5 \times 23 \mathrm{~cm})$ similar to the ones used by Stears et al. (2014). The second had the same dimensions, but was white. Finally, the third patch comprised a small black circular plastic tray $(45 \mathrm{~cm}$ diameter and $10 \mathrm{~cm}$ deep). The black rectangular patch contained $300 \mathrm{~g}$ of commercial sheep food, the white rectangle contained $100 \mathrm{~g}$, and the small round patch contained $40 \mathrm{~g}$. We used different trays of different colour and size to help the goats differentiate between different food availabilities. To provide diminishing returns and prevent all the food from being consumed from the patches in the trials, we filled the rectangular patches with $5 \ell$ of inedible substrate comprising equal amounts of dried corncobs and plastic tubes $(20 \mathrm{~cm}$ in length and $3 \mathrm{~cm}$ diameter), while the round patch was filled with $2.5 \ell$ of this mixture. The difference in the amount of inedible substrate between patches resulted in a positive relationship between food quantity and food per volume of substrate. Specifically, there was $16 \mathrm{~g} / \ell$ in the $40 \mathrm{~g}$ patch (i.e. $40 \mathrm{~g} / 2.5 \ell$ ), $20 \mathrm{~g} / \ell$ in the $100 \mathrm{~g}$ patch (i.e. $100 \mathrm{~g} / 5 \ell$ ), and $60 \mathrm{~g}$ of food/ $\ell$ of inedible substrate in the $300 \mathrm{~g}$ patch (i.e. $300 \mathrm{~g} / 5$ $\ell$ ). We then attached a $3 \times 3$ grid of $0.2 \mathrm{~cm}$ wire on the top of all the patches to prevent the goats from moving their feet or muzzle across the full length of the artificial patches, and thus pushing out large amounts of the substrate.

Prior to the experiments, we trained the dominant goats to associate the different colours and shapes of the patches with the different food quantities. We did this by simultaneously providing a dominant goat with all the different food availability patches and allowed the goat to feed for 5 minutes. This gave the goat enough time to assess each food availability by repeatedly feeding and moving among the different patches. In addition, it allowed the dominant goats to become accustomed to feeding in the testing arena (Figure 1). 
We repeated this process twice a day (early morning and late afternoon) in the testing area each day for 30 days.

After this training period, we then tested whether these goats could visually differentiate the patches. We used a patch choice experiment involving a sequence of binary choices between the different patches (e.g. black rectangle vs. black circle, black rectangle vs. white rectangle, etc.). We conducted these experiments in the testing arena with a different patch on each side of the divider (Figure 1). For these experiments, there was no goat tethered behind the food patches. A test goat was held at the front of the arena in line with the divider ca. $6 \mathrm{~m}$ from the patches, which allowed it to see both patches. We then released the goat and recorded the first patch it chose. In all instances, the goats walked straight to a patch and started feeding. No individuals moved between patches after a choice was made. We tested all dominant individuals each day, but only exposed them to one patch-choice combination per day. Patch combinations (i.e. 40 vs. 100 g, 40 vs. 300 g, or 100 vs. 300 g) and whether the patch with the larger food availability was on the left or right of the divider was randomised for each goat each day. To ensure that the goats could differentiate between the different patches, we tested each goat twice for each food availability combination. This resulted in six days of testing. Despite most of the dominant goats being able to identify the patch with the most food (see Results), we only used a dominant goat in our experiments if it consistently differentiated between all the different food availability combinations.

\section{Finder's share}

To determine whether the scrounging goats incorporated a finder's share into their patchjoining decisions, we provided a test goat with a choice between two patches with a subordinate goat tethered behind each patch. One of these patches had the finder's share removed (i.e. subordinate goat had been allowed to feed), and at the other patch the 
subordinate had not fed. For these experiments, we used patches of equal food availability because we were only interested in comparing patch-joining decisions between patches where the only difference was whether the finder's share had been removed or not.

To record patch choice, we held the test goat at the front of the testing area (Figure 1). Then while it watched, we placed an artificial patch in front of one tethered subordinate individual. To alter the finder's share, we allowed the tethered goat to feed from the food patch for a given time period (i.e. $0 \mathrm{~s}, 10 \mathrm{~s}, 30 \mathrm{~s}, 60 \mathrm{~s}$, or $120 \mathrm{~s}$ ). These times provided an index of the amount of food removed (i.e. the finder's share) (Di Bitetti \& Janson, 2001). After the subordinate goat had fed for the designated time, we then placed a food patch in front of the second tethered subordinate goat. Two seconds after putting the second patch down, we released the test goat and recorded which patch it selected.

Once the scrounging goat made a decision and entered a side of the divider, we did not allow it to feed from the patch because we wanted to calculate the finder's share obtained by the patch holder. However, to avoid the possibility of a lack of food from influencing the scrounging goat's decision in subsequent experiments, we allowed the scrounging goat to feed from a separate feeding patch of the same food availability (i.e. $40 \mathrm{~g}, 100 \mathrm{~g}$, or $300 \mathrm{~g}$ ) that was used in the trial. It is possible that by allowing the scrounging goat to feed, we provided positive reinforcement for when it made "bad" decisions (i.e. selected the finder's share patch). To counteract this, we only allowed the scrounging goats to feed for $10 \mathrm{sec}$ irrespective of the patch they chose. Thus, these goats only received a small amount of food regardless of their decisions.

After each trial, we emptied the remaining food from the patches and weighed it to determine the actual finder's share obtained. We then refilled the patches for the next test goat. To control for a potential side effect, we randomized the side of the goat obtaining a finder's share for each trial. We tested all 19 dominant individuals during a single morning, 
but only provided one patch $(40 \mathrm{~g}, 100 \mathrm{~g}, 300 \mathrm{~g}) /$ finder's share combination $(0 \mathrm{~s}, 10 \mathrm{~s}, 30 \mathrm{~s}$, $60 \mathrm{~s}, 120 \mathrm{~s}$ ) per goat per day. This resulted in 15 days of testing (i.e. 3 patch qualities x 5 finder's shares). Finder's share combination and food availability were randomised daily for each test goat (i.e. there was no consecutive increase in finder's share combination or food availability), but all test goats experienced each patch/finder's share combination over the 15 days. In addition, we used a new combination of subordinate goats for each test goat each day. However, due to the number of subordinates that were needed, we used some subordinates more than once a day. These re-used goats were not used to calculate the finder's share, but were used at the other patch. This avoided having prior food consumption influence the feeding behaviour of these patch holders. To ensure that these re-used subordinates remained focused, a subordinate only participated in a maximum of two trials per day, and these trails were separated by at least 10 other trails.

\section{Data Analysis}

Dominance interactions were calculated using DomiCalc (Schmid \& de Vries, 2013). For this study, we were not interested in the exact dominance position of each goat in the herd. Rather, we used the hierarchy to ensure that the dominant patch joiners in the patch-joining experiments were always dominant over the subordinate patch holders. Furthermore, to avoid potential dominance-subordinate reversals (Barosso, Alados, \& Boza, 2000; Reinhardt \& Flood, 1983), we never tested individuals that were close in rank. In addition, we ensured that five ranks were left between the lowest ranked dominant goat (i.e. IG57) and the highest ranked subordinate (i.e. IG44; see the gap of five consecutive individuals labelled as "not used" in Table 1).

To assess whether the goats could visually differentiate between the various patches ( $40 \mathrm{~g}, 100 \mathrm{~g}$, and $300 \mathrm{~g}$ ) we analysed the proportion of visits by the goats to the patch with 
more food for each food availability combination (i.e. 40 g vs. 100 g, 40 g vs. 300 g, and 100 g vs. 300 g). This choice experiment involved a sequence of binary choices between two feeding patches. For each of these experiments, we tested the same goats over consecutive days. Thus, data were not independent. To account for this, we treated each test goat as the subject of repeated measures in Generalized Estimating Equations (GEEs). The model incorporated an exchangeable correlation matrix, binomial error distribution and a logit link function. For graphical representation, we back-transformed data from the logit scale, resulting in asymmetrical confidence intervals (CIs). The means and 95\% CIs were used to determine whether the goat's preference between patches differed significantly from the expected $50 \%$ visit to each patch type under random visitation for each food availability combination.

To explore the relationship between the time a patch holder spent feeding $(10 \mathrm{~s}, 30 \mathrm{~s}$, $60 \mathrm{~s}, 120 \mathrm{~s}$ ), food availability (40 g, $100 \mathrm{~g}$, and $300 \mathrm{~g}$ ), and the proportion of food eaten by the patch-holder (i.e. finder's share), we ran a GEE because we tested the same goats over consecutive days. Because the data were proportional, we used a binomial distribution with a Logit link function and an exchangeable correlation matrix. The response variable was the proportion of food eaten by the patch holder. We included food availability, time spent feeding by the patch holder, and their interaction as independent variables. The dependent variable was back-transformed from the logit scale.

Finally, to determine how finder's share and food availability influenced patch selection, we analysed the scrounging goats' patch choice using GEEs. This model incorporated an exchangeable correlation matrix, binomial error distribution and a logit link function. The response variable was choice $(1=$ the scrounging goat fed from the finder's share patch, $0=$ the scrounging goat fed from the other patch), and the factors were feeding time $(0 \mathrm{~s}, 10 \mathrm{~s}, 30 \mathrm{~s}, 60 \mathrm{~s}$, and $120 \mathrm{~s})$, food availability $(40 \mathrm{~g}, 100 \mathrm{~g}$, and $300 \mathrm{~g})$ and their 
interaction. As with the first GEE, we back-transformed the data from the logit scale creating asymmetrical confident intervals (CI). The mean and CIs were used to assess preference, no preference, or avoidance of the finder's share feeding patch based on a $50 \%$ choice expected under random distribution. For our analyses, we used GEEs because GEEs use a populationlevel approach based on quasi-likelihood function, provide population-averaged estimates of the parameters, and the coefficients of GEE regressions are marginal effects (i.e. the effects average across all the subjects in the data) (see Wang 2014 and references therein). With the marginal model, the concern does not lie with the difference in patch choice among individual goats, rather how patch choice is influence by food availability and feeding time. If the overall treatment effect is of primary interest, a GEE is preferred (Wang 2014). A major advantage to a GEE is its robustness on the structure of the working correlation matrix. The parameter estimator and its covariance matrix can be consistently estimated, by using robust "sandwich" variance estimator, even if an incorrect working correlation matrix is used (see Wang 2014). All statistical analyses were run with IBM SPSS v. 24 (IBM Inc.).

\section{Results}

In the patch choice experiment, dominant goats showed a clear preference for the patch with the higher food availability (Figure 2). These goats fed from these patches $84 \%$ to $100 \%$ of the time, which differed significantly from the $50 \%$ expected if they selected randomly. From the dominant goats that were tested, we chose 19 that consistently chose the patch with the higher food availability to use as scroungers in our experiments. 


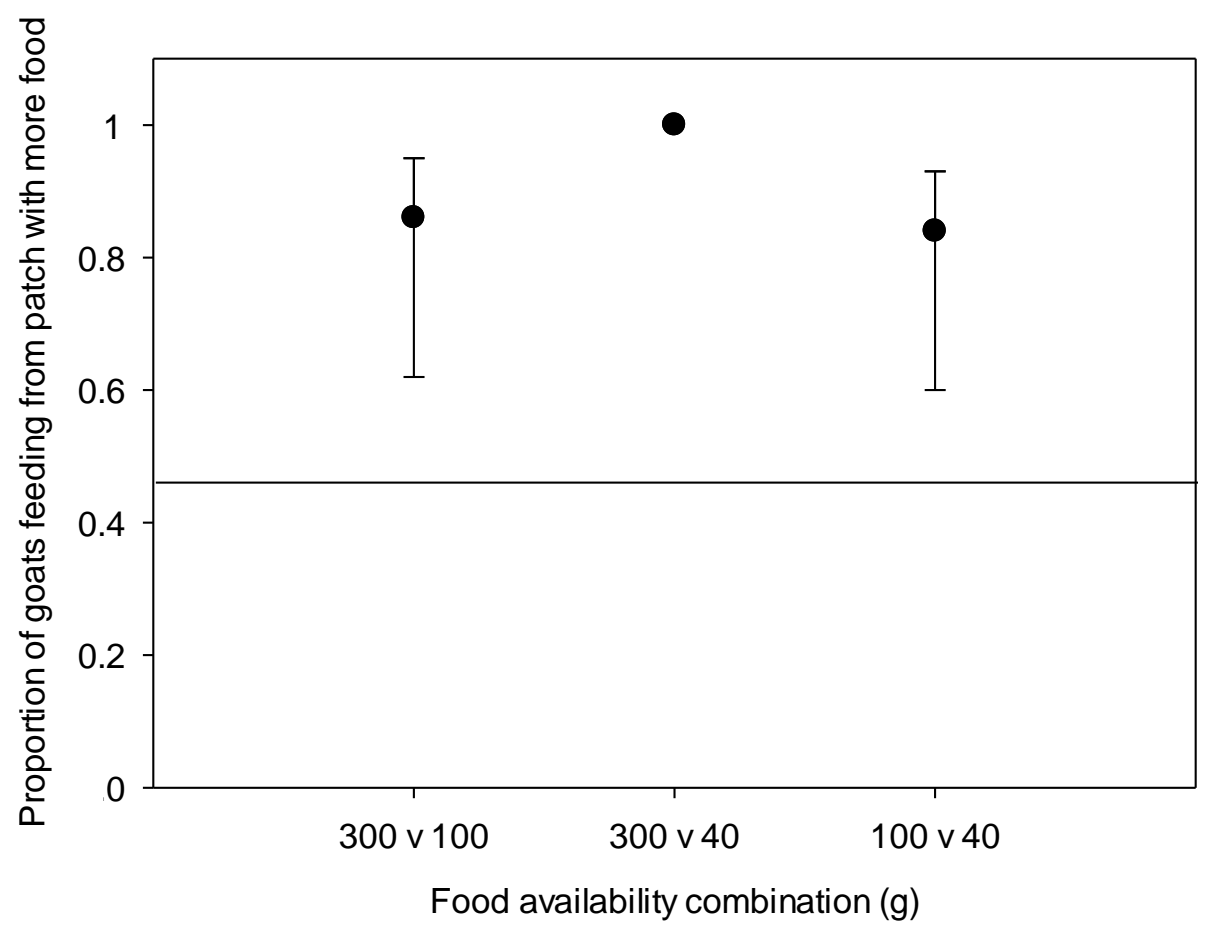

Figure 2. Marginal means of the proportion of goats feeding from the patch with more food $( \pm 95 \% \mathrm{CI})$ are plotted. Overlap between the confidence intervals and the 0.5 distribution expected under random visitation indicates no preference. Mean above the 0.5 distribution and $95 \%$ CIs that do not overlap, indicates a preference for the patch with more food.

The additive effects of feeding time and the availability of food in a patch significantly influenced finder's share $\left(\chi^{2}=158.647, P<0.001\right.$; Figure 3). Specifically, patch holders that fed for longer obtained a larger finder's share $\left(\chi^{2}=1012.387, P<0.001\right.$; Figure 3). However, the proportion of food that patch holders gained declined as food availability increased $\left(\chi^{2}=1145.582, P<0.001\right.$; Figure 3$)$. Thus, patch holders ate a greater proportion of the food (i.e. larger relative finder's share) in patches with low food availability compared to patches with higher food availability. 


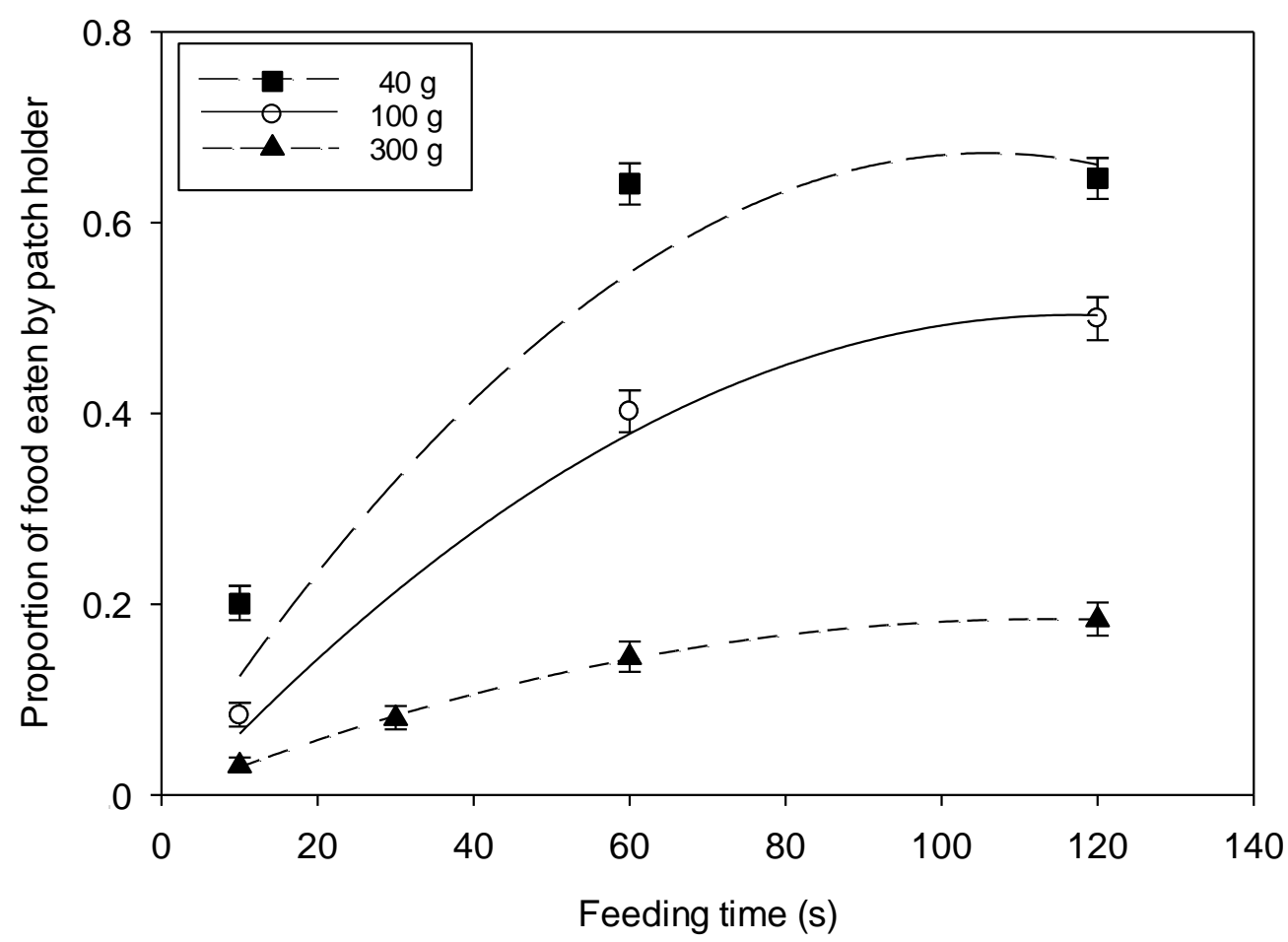

Figure 3. Proportion of food eaten from a patch (i.e. finder's share) by subordinate patch holders in relation to time spent feeding in a patch $(10 \mathrm{~s}, 30 \mathrm{~s}, 60 \mathrm{~s}, 120 \mathrm{~s})$, and the availability of food in the patch $(40 \mathrm{~g}, 100 \mathrm{~g}, 300$ $\mathrm{g})$. Note, at $30 \mathrm{~s}$ feeding time the proportion of food eaten by the patch holder is the same for $40 \mathrm{~g}$ and $100 \mathrm{~g}$.

\section{Finder's Share}

Food availability in a patch $\left(\chi^{2}=24.401, P<0.001\right.$ ), feeding time (i.e. finder's share removed) $\left(\chi^{2}=20.435, P<0.001\right)$, and the interaction of these two variables $\left(\chi^{2}=30.589, P\right.$ $<0.001$ ), had significant effects on the patch-joining decisions of the scrounging goats. At the low (40 g) and intermediate (100 g) food availabilities, scroungers avoided the finder's share patch after the subordinate patch holder had only been feeding for $\geq 30$ seconds. At both these food availabilities, scrounging goats avoided joining the finder's share patch when $\sim 80 \%$ of the food was still available to the scrounger (i.e. $32 \mathrm{~g}$ and $80 \mathrm{~g}$ respectively; Figures $4 \mathrm{a} \&$ b). However, at the highest food availability (i.e. $300 \mathrm{~g}$ ), scrounging goats were not deterred by the removal of the finder's share, and continued to join the finder's share patch, even if the subordinate patch holder had fed for 120 s (i.e. $18 \%$ of the food removed; Figure 4c). At this 


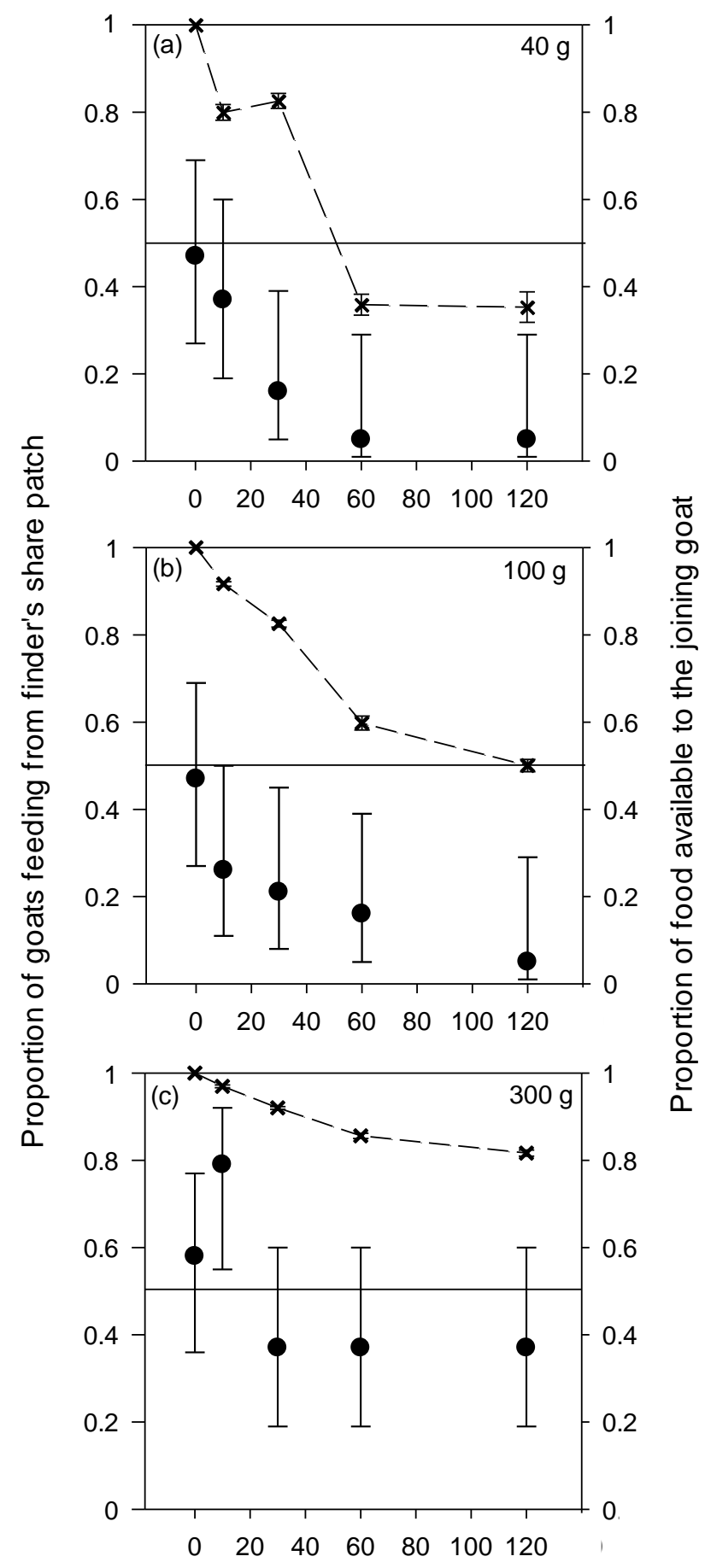

Feeding time (s)

Figure 4 a-c. Proportion ( \pm SE) of food available to the scrounging goat and the marginal means $( \pm 95 \% \mathrm{CI})$ of the proportion of goats feeding from the finder's share patch against feeding time for three different food availabilities: (a) $40 \mathrm{~g}$, (b) $100 \mathrm{~g}$, and (c) $300 \mathrm{~g}$. Overlapping 95\% CI with the 0.5 expectation under random visitation indicates no significant preference for either patch (i.e. finder's share and other patch). When the mean was below the 0.5 expectation under random visitation and $95 \%$ CIs do not overlap, it indicates avoidance of the finder's share patch. 
food availability, more than $80 \%$ of the food was still available to the scrounging goat even when the patch holder had been feeding for $120 \mathrm{~s}$ (Figure 4c). At $300 \mathrm{~g}$, the majority of scrounging goats preferred to feed from the finder's share patch at $10 \mathrm{~s}$ and did not exhibit a random distribution that was observed at the other feeding times (Figure 4c).

\section{Discussion}

Group-living herbivores can use a number of cues to locate and determine whether they should join patches held by other group members (Shrader et al., 2007; Stears et al., 2014). We found that feeding time (an index of finder's share removed), and food availability in a patch, influenced the patch-joining decisions of scrounging goats. However, the importance of the removal of the finder's share in determining whether an individual joined a patch declined as the availability of food in a patch increased. Moreover, our results highlight that finder's share can impact foraging decisions via influencing which patches individuals join. Thus, we suggest that individuals likely have flexibility in how they react to varying finder's shares, and that finder's share may not only influence the overall foraging strategy, but also the patches which individuals join.

To accurately assess the removal of the finder's share, group-living herbivores need to monitor the foraging behaviour of other herd members (i.e. social monitoring; Favreau, Goldizen, \& Pays, 2010). For large mammalian herbivores, obtaining social information occurs primarily during processing and potentially digestive time, thus it can be obtained with very little influence on the intake rate of the potential scrounger (Fortin, Boyce, Merrill, \& Fryxell, 2004). In addition, given the position of the eyes of many herbivores, it is likely that they may be able to obtain social information about which patch to join without having to lift their heads (see Harman, Moore, Hoskins, \& Keller, 1999). If this is the case, then this increases the ability of scroungers to continuously monitor the foraging of other group 
members. This would then allow these scroungers to make more informed patch-joining decisions, while at the same time maintaining their own foraging.

The use of the finder's share as a cue for making patch-joining decisions is likely prevalent in both large and small groups. In small groups, potential scroungers likely gain finder's share information from a majority of group members. Yet, as group size increases, so too does the number of potential competitors, which increases the frequency of social monitoring (Favreau et al., 2010). However, the ability of goats, and other social herbivores, to keep track of when every herd member started to feed (and thus estimate finder's share) may be limited by their cognitive ability, despite the noted intelligence of goats (Briefer, Padilla de la Torre, \& McElligott, 2012; Briefer, Haque, Baciadonna, \& McElligott, 2014). Furthermore, as the number of herd members increases, individuals increasingly block the sightlines of scrounging individuals, likely preventing them from monitoring the activities of all group members (Bekoff, 1995). Thus, in these larger groups, scroungers may not have complete information of all available patches, and therefore likely make patch-joining decisions based on the more limited information obtained from the surrounding group members that they can monitor.

The fact that the scrounging goats considered both the time that a patch-holder fed (i.e. finder's share) and the initial food availability of a patch when making patch-joining decisions, suggests that there was a point where the unexploited patch was perceived to be more profitable than the finder's share patch. Patch profitability is likely assessed using the amount of food available to the scrounging goat as well as the potential intake rate, which we would expect to decrease as food availability decreased because of increasing search time. Not surprisingly, patches containing less food (40 g, $100 \mathrm{~g}$ ), became less profitable quicker compared to the patch with the greatest food availability (300 g). This was likely because patch holders (i.e. producers) were able to reduce food availability in these smaller patches to 
lower overall levels. For example, after 30 seconds of feeding by the patch-holder, the $40 \mathrm{~g}$ patches retained only $30 \mathrm{~g}$ of food, and the $100 \mathrm{~g}$ patches had $83 \mathrm{~g}$, while the $300 \mathrm{~g}$ patch still contained $270 \mathrm{~g}$.

In response to the rapid decrease in food availability in the $40 \mathrm{~g}$ and $100 \mathrm{~g}$ patches, we found that scrounging goats tended to make cautious foraging decisions. For example, when choosing between a patch where the patch holder had fed for only 30 seconds and an unexploited patch, scroungers preferred the unexploited patch, despite the finder's share patch still being profitable (i.e. $80 \%$ of the food available). It is likely that scroungers did this to limit situations where they would obtain inadequate intakes. In contrast, in the $300 \mathrm{~g}$ patch, the slow depletion of food (Figure 3) would likely have very little effect on the scrounger's intake, especially because after $120 \mathrm{~s}$ there was still $246 \mathrm{~g}$ of food remaining in the patch. As a result, in the $300 \mathrm{~g}$ patch, there was no need to switch and utilise the unexploited patch. Yet, with this in mind, we are uncertain as to why the scrounging goats preferred feeding from the $300 \mathrm{~g}$ patches when the patch holder had fed for $10 \mathrm{~s}$.

Overall, we expected scrounging goats to show an increasing tolerance to the removal of the finder's share, with increasing food availability. However, we found that these goats viewed both the $40 \mathrm{~g}$ and $100 \mathrm{~g}$ patches similarly with regards to how long they would tolerate a patch-holder feeding, before avoiding the patch. A potential explanation for this is that the goats were limited in their ability to accurately assess the rate at which food was removed by the patch holders. Yet, as the grams of food per litre of substrate were similar in the two patches (i.e. $100 \mathrm{~g}=20 \mathrm{~g} / \ell, 40 \mathrm{~g}=16 \mathrm{~g} / \ell$ ), the removal of the finder's share likely had similar impacts on the potential intake rate that could be achieved by the scroungers in the two patches. Thus, the similar feeding tactics displayed by the scrounging goats more likely reflects these goats maximising potential food intake in the patches. 
Ultimately, our results highlight that goats weigh up the costs and benefits of both food availability and time spent feeding by a patch holder (i.e. the finder's share) when making patch-joining decisions. With regards to producer-scrounger theory, our results show that the influence of finder's share goes beyond simply effecting the proportion of producers and scroungers in a population (Giraldeau \& Livoreil, 1998; Giraldeau \& Caraco, 2000). Rather, it also directly influences the patch-joining decisions of scroungers. As a large number of animals live in groups (e.g. Barnard \& Sibley, 1981; Krause \& Ruxton 2002; Pays, Benhamou, Helder, \& Gerard, 2007), the use of finder's share as a cue for patch joining is likely a widespread phenomenon. If so, then by being visually cognisant of the availability of food in patches (Illius, Clark, \& Hodgson, 1992; Stutz, Croak, Proschogo, Banks, \& McArthur, In press) and finder's share removal, scroungers should be better able to focus their joining towards patches with more food. This information, coupled with information on the dominance status of the patch holder (Stears et al., 2014), likely helps scroungers to reduce overall search time while foraging, minimise aggressive interactions, and as a result maximise food intake.

\section{References}

Aschwanden, J., Gygax, L., Wechsler, B., \& Keil, N. M. (2008). Social distances of goats at the feeding rack: influences of the quality of social bonds, rank differences, grouping age and presence of horns. Applied Animal Behaviour Science, 114, 116-131.

Bang, A., Deshpande, S., Sumana, A., \& Gadagkar, R. (2010). Choosing an appropriate index to construct dominance hierarchies in animal societies: a comparison of three indices. Animal Behaviour, 79, 631-636. 
Barnard, C. J. (1984). The evolution of food-scrounging strategies within and between species. In: C. J. Barnard (Ed.), Producers and scroungers: a general model and its application and parasitism (pp. 95-126). New York: Chapman and Hall.

Barnard, C. J., \& Sibley, R. M. (1981). Producers and scroungers: a general model and its application to captive flocks of house sparrows. Animal Behaviour, 29, 543-550.

Barroso, F. G., Alados, C. L., \& Boza, J. (2000). Social hierarchy in the domestic goat: effect on food habits and production. Applied Animal Behaviour Science, 69, 35-53.

Barta, Z., \& Giraldeau, L. A. (1998). The effect of dominance hierarchy on the use of alternative foraging tactics: a phenotype-limited producing-scrounging game. Behavioral Ecology and Sociobiology, 42, 217-223.

Beauchamp, G. (2008). A spatial model for producing and scrounging. Animal Behaviour, 76, 1935-1942.

Bekoff, M. (1995). Vigilance, flock size, and flock geometry: Information gathering by western evening grosbeaks (Aves, Fringillidae). Ethology, 99, 150-161.

Briefer, E. F., Padilla de la Torre, M., \& McElligott, A. G. (2012). Mother goats do not forget their kid's calls. Proceedings of the Royal Society B, 279, 2749-3755.

Briefer, E. F., Haque, S., Baciadonna, L., \& McElligott, A. G. (2014). Goats excel at learning and remembering a highly novel cognitive task. Frontiers in Zoology, 11, 20. DOI: 10.1186/1742-9994-11-20.

Caraco, T., \& Giraldeau, L. A. (1991). Social foraging: producing and scrounging in a stochastic environment. Journal of Theoretical Biology, 153, 559-583.

Cote, S. D. (2000). Dominance hierarchies in female mountain goats: stability, aggressiveness and determinants of rank. Behaviour, 137, 1541-1566.

Di Bitetti, M. S., \& Janson, C. H. (2001). Social foraging and finder's share in capuchin monkey, Cebus paella. Animal Behaviour, 62, 47-56. 
Favreau, F. -R., Goldizen, A. W. \& Pays, O. (2010). Interactions among social monitoring, anti-predator vigilance and group size in eastern grey kangaroos. Proceedings of the Royal Society B, 277, 2089-2095.

Fortin, D., Boyce, M. S., Merrill, E. H., \& Fryxell. J. M. (2004). Foraging costs of vigilance in large mammalian herbivores. Oikos, 107, 172-180.

Gammell, M. P., De Vries, H., Jennings, D .J., Carlin, C. M., \& Hayden, T.J. (2003). David's score: a more appropriate dominance ranking method than Clutton-Brock et al.'s index. Animal Behaviour, 66, 601-605.

Giraldeau, L.-A., \& Beauchamp, G. (1999). Food exploitation: searching for the optimal joining policy. Trends in Ecology and Evolution, 14, 102-106.

Giraldeau, L.-A., \& Caraco, T. (2000). Social foraging theory. Princeton, New Jersey: Princeton University Press.

Giraldeau, L. A., \& Dubois, F. (2008). Social foraging and the study of exploitative behaviour. Advances in the Study of Behavior, 28, 59-104.

Giraldeau, L. A., Hogan, J. A., \& Clinchy, M. J. (1990). The payoff to producing and scrounging: what happens when patches are divisible? Ethology, 85, 132-246.

Giraldeau, L. A., \& Livoreil, B. (1998). Game theory and social foraging. In L. A. Dugatkin \& H. K. Reeve (Eds.), Game theory and animal behaviour (pp. 16-37). Oxford, U.K.: Oxford University Press.

Giraldeau, L. A., Valone, T. J., \& Templeton, J. J. (2002). Potential disadvantages of using socially acquired information. Philosophical Transactions of Royal Society of London: Biological Sciences, 357, 1559-1566.

Hamilton, I. M. (2002). Kleptoparasitism and the distribution of unequal competitors. Behavioural Ecology, 13, 260-267. 
Harman, A. M., Moore, S., Hoskins, R., \& Keller, P. (1999). Horse vision and an explanation for the visual behaviour originally explained by the 'ramp retina'. Equine Veterinary Journal, 31, 384-390.

Illius, A. W., Clark, D. A., \& Hodgson, J. (1992). Discrimination and patch choice by sheep grazing grass-clover swards. Journal of Animal Ecology 61, 183-194.

Jarman, P. J. (1974). The social organisation of antelope in relation to their ecology. Behaviour, 48, 215-267.

King, A. J., Isaac, N. J. B., \& Cowlishaw, G. (2009). Ecological, social, and reproductive factors shape producer-scrounger dynamics in baboons. Behavioral Ecology, 20, 1039-1049.

Krause, J., \& Ruxton, G. D. (2002). Living in groups. New York: Oxford University Press.

Lima, S. L. (1990). The influence of models on the interpretation of vigilance. In: M. Bekoff, \& D. Jamieson (Eds.), Interpretation and explanation in the study of animal behaviour: Explanation, evolution and adaption. (pp. 246-267). California: Westview Press.

Liker, A., \& Barta, Z. (2002). The effects of dominance on social foraging tactic use in house sparrows. Behaviour, 139, 1061-1076.

Loretz, C., Wechsler, B., Hauser, R., \& Rüsch, P., (2004). A comparison of space requirements of horned and hornless goats at the feed barrier and in the lying area. Applied Animal Behavior Science, 87, 275-283

Ohtsuka, Y., \& Toquenaga, Y. (2009). The patch distributed producer-scrounger game. Journal of Theoretical Biology, 260, 261-266.

Pays, O., Benhamou, S., Helder, R. \& Gerard, J.-F. (2007). The dynamics of group formation in large mammalian herbivores: an analysis in the European roe deer. Animal Behaviour, 74, 1429-1441. 
Reinhardt, V., \& Flood, P.F. (1983). Behavioural assessment in muskox calves. Behaviour, $87,1-21$.

Schmid, V. S., \& de Vries, H. (2013). Finding a dominance order most consistent with a linear hierarchy: an improved algorithm for the I\&SI method. Animal Behaviour, 86, $1097-1105$.

Schmitt, M. H., Stears, K., Wilmers, C., Shrader, A. M. (2014). Determining the relative importance of dilution and detection for zebra foraging in mixed-species herds. Animal Behaviour, 96, 151-158.

Schmitt, M. H., Stears, K. \& Shrader, A. M. (2016). Zebra reduce predation risk by eavesdropping on cues from giraffe. Behavioral Ecology, 27, 1073-1077.

Shrader, A. M., Kerley, G. I. H., Brown, J. S., \& Kotler, B. P. (2012). Patch use in freeranging goats: does a large mammalian herbivore forage like other central place foragers? Ethology, 118, 967-974.

Shrader, A. M., Kerley, G. I. H., Kotler, B. P., \& Brown, J. S. (2007). Social information, social feeding, and competition in group-living goats (Capra hircus). Behavioral Ecology, 18, 103-107.

Stears, K., Kerley, G. I. H. \& Shrader, A. M. (2014). Group-Living herbivores weigh up food availability and dominance status when making patch-joining decisions. PLoS ONE, 9, e109011.

Stutz, R. S., Croak, B. M., Proschogo, N., Banks, P. B. \& McArthur, C. (In press). Olfactory and visual plant cues as drivers of selective herbivory. Oikos. DOI: 10.1111/oik.03422.

Valone, T. J. (1989). Group foraging, public information, and patch estimation. Oikos, 56, $357-363$. 
Valone, T. J., \& Templeton, J. J. (2002). Public information for the assessment of quality: a widespread social phenomenon. Philosophical Transactions of Royal Society of London: Biological Sciences, 357, 1549-1557.

Vickery, W., Giraldeau, L. A., Templeton, J. J., Kramer, D. L., \& Chapman, C. A. (1991). Producer, scroungers, and group foraging. The American Naturalist, 137, 847-863.

Wang, M. (2014). Generalized estimating equations in longitudinal data analysis: a review and recent developments. Advances in Statistics, 2014, 1-11. 